SciDioc

International Journal of Dentistry and Oral Science (IJDOS)

ISSN: $2377-8075$

\title{
Knowledge, Awareness and Perception Among Dental Practitioners Regarding Direct and Indirect Method Of Composite Restoration For Class I Cavity
}

Research Article

Santhosh kumar ${ }^{1 *}$, Keerthana Baskar ${ }^{2}$, Aishwarya Ranganath ${ }^{3}$

${ }^{1}$ Reader, Department of Oral and Maxillofacial Surgery, Saveetha Dental College and Hospital, Saveetha University.

${ }^{2}$ Department of Oral and Maxillofacial Surgery, Saveetha Dental College and Hospital, Saveetha University.

${ }^{3}$ Senior lecturer, Department of Conservative dentistry and Endodontics, Saveetha Dental College and Hospital, Saveetha University.

Abstract

Introduction: Composite restorations have made a revolution in conservative dentistry due to their adhesive bonding ability and aesthetics which has increased patient appeal. The adhesive bonding ability of composite resin, makes it unnecessary to remove tooth structure for retention, prevention and convenience. Hence, this leads to successful restorations that can be done with less precise preparations.

Objective: The main aim of this study was to assess the knowledge, awareness and perception regarding direct and indirect method of composite restoration for class I cavity among dental practitioners in our region.

Methods: This cross-sectional study was conducted among 100 dental practitioners in Chennai city, using a self-administered questionnaire consisting of 18 validated and structured questions. Data obtained was statistically analysed and results obtained. Results: About $85 \%$ of the dentists knew the different methods of composite restoration. $56 \%$ of them felt that direct method is more efficient than indirect restoration. Majority of the dentists $(69 \%)$ followed direct technique in their practice. Conclusion: From our study it is evident that, dentists knew the method of indirect restoration, although most of them did not find this technique to be effective and hence did not practice. It is necessary to create awareness among the clinicians to practice indirect restoration technique for suitable patients with class I cavities.

Keywords: Composite Resin; Dental Cavity; Dental Restoration; Class I Cavity; Restorative Dentistry; Aesthetics; Retention; Marginal Integrity.

\section{Introduction}

In today's world, there is an increase in the demand for aesthetics that has led to the development of tooth-coloured, non-metallic restorations such as direct composite restorations, indirect composite inlays, and ceramic inlays or onlays [1]. Composite restorations have made a revolution in conservative dentistry due to their adhesive bonding ability and aesthetic which has increased patient appeal. The adhesive bonding ability of composite resin, makes it unnecessary to remove tooth structure for retention, prevention, and convenience. Hence, this leads to successful restorations that can be done with less precise preparations [2].

Composite inlays were first proposed by Touati of France and James of United states of America. They made incrustations of moulded composite from an impression which was secondarily bonded in the mouth. These incrustations that were bonded were later named as composite inlays [3, 4]. The most commonly used composite materials are hybrid, micro-filled and nano-filled composites for posterior restorations. The filler loading in Microfilled composites is $37 \%-40 \%$, where as nano-filled composites have $60 \%$ volume filler loading [2]. Nano-filled composites show high translucency similar to micro-filled composites and physical properties similar to hybrid composite [5]. Other advantages apart

*Corresponding Author:

Santhosh kumar,

Reader, Department of Oral and Maxillofacial Surgery, Saveetha Dental College and Hospital, Saveetha Institute of Medical and Technical Sciences (SIMATS) Saveetha University 162, Poonamallee High Road, Velappanchavadi, Chennai 600077 Tamil Nadu, India. Tel: 9994892022

Email Id: santhoshkumar@saveetha.com

Received: March 01, 2021

Accepted: March 20, 2021

Published: April 02, 2021

Citation: Santhosh kumar, Keerthana Baskar, Aishwarya Ranganath. Knowledge, Awareness and Perception Among Dental Practitioners Regarding Direct and Indirect Method Of Composite Restoration For Class I Cavity. Int J Dentistry Oral Sci. 2021;08(04):2162-2165. doi: http://dx.doi.org/10.19070/2377-8075-21000427

Copyright: Santhosh kumar 2021 . This is an open-access article distributed under the terms of the Creative Commons Attribution License, which permits unrestricted use, distribution and reproduction in any medium, provided the original author and source are credited. 
from aesthetics are that these materials are relatively less expensive, induce lesser wear of opposing tooth structure and are based on the principle of minimally invasive procedure [6].

There are various techniques for placing composite resin restorations. It includes the direct and the indirect technique. The selection between direct and indirect technique is a challenging process. The advantage of single visit direct posterior composite restorations is the preservation of tooth structure [7]. The procedure in this technique includes etching and application of bonding agent to the prepared cavity, composite restoration is built up in increments, curing one layer at a time while allowing the practitioner to sculpt the restoration. Hence, cavities are filled incrementally. The layering technique, thus, effectively reduces the polymerization stress by minimizing the $\mathrm{C}$-factor, which in turn increases the bond strength.

Advantages of direct technique include increased strength of remaining tooth structure and potential for repair, while the major disadvantages are themechanical strength of these restorations is inferior to that of indirect composite restorations. Other disadvantages include occlusal and proximal wear, surface roughness, marginal discoloration, loss of marginal integrity, postoperative sensitivity, secondary caries, cusp flexure, technique sensitive, lessthan-ideal bonding to dentin, and low fracture toughness [7].

Fabrication of the restoration outside the oral cavity in the laboratory, following which it is luted to the tooth with resin cement is referred to as Indirect technique. There are two types of indirect composite restorations, which include the first and second generation. The first generation of indirect restoration resins have shown failures in clinical studies. In spite of their secondary curing, they exhibited low levels of flexural strength (60-80 MPa) and elastic modulus $(2-3.5 \mathrm{GPa})$; a resin volume more than $50 \%$ and higher wear levels [8]. A second generation of indirect composites was introduced which included micro-hybrid composites with fillers of approximately $66 \%$ by volume, to overcome the disadvantages of first-generation indirect composites. These composites had improved mechanical properties with flexural strength in the range of $120-160 \mathrm{MPa}$ and elastic modulus of $8.5-12 \mathrm{GPa}$ [9].

The fabrication process differs for direct composite restoration and indirect inlays. For direct composite, first a separating medium is applied to the prepared tooth. The resin pattern is then formed, light-cured and removed from the preparation. The rough inlay is then exposed to additional light for approximately 4-6 min or heat activated at $110^{\circ} \mathrm{C}$ for $7 \mathrm{~min}$, after which the preparation is etched, the inlay is cemented in to place with a dualcure resin, and is then polished. This technique can be completed in a single sitting since it eliminates the need for an impression of the cavity [10].

Indirect inlay system requires an impression to fabricate the inlay in the laboratory. It is important that the work done in the laboratory should co-ordinate to those done in the clinic to facilitate good bonding, fitting and occlusion of the inlay. In addition to conventional light-curing and heat-curing for polymerization, laboratory processing may use heat $\left(140^{\circ} \mathrm{C}\right)$, pressure $(0.6 \mathrm{MPa}$ for $10 \mathrm{~min}$ ) and nitrogen atmosphere. These materials have improved physical properties, resistance to wear and attain a higher degree of polymerization [11].
The advantages of Composite inlays are that they provide better contouring of proximal surfaces, occlusal contacts, improved wear resistance, reduced polymerization shrinkage, improved fracture resistance, and biocompatibility [11]. The indirect composite inlay offers better control of cervical tightness and better restitution of the contact point in cases of proximal loss of substance [12]. The drawbacks of composite inlays are increased cost and time, requires two appointments, fabrication of a temporary restoration, and low potential for repair. Secondary caries with composites to some extent is associated to the restorative material, as significantly more caries occurs with composites than with amalgam [13].

Hence, the selection between direct and indirect composite restorations is challenging. Many clinical studies have been performed on success or survival rate of direct and indirect composite restorations individually [14-20]. Very few articles have studied comparing direct versus indirect composite restorations [21, 22]. Hence, the primary objective of this study was to assess the knowledge, awareness and perception regarding direct and indirect method of composite restoration for class I cavity among dental practitioners in our region.

\section{Materials and Methods}

A cross-sectional study was conducted among 100 dental practitioners in Chennai city, to assess theKnowledge, Awareness and Perception regarding Direct and Indirect Method of Composite Restoration in Class I Cavity. Data were gathered with a self-administered questionnaire consisting of 18 validated and structured questions [Figure 1]. Data obtained was statistically analysed, results obtained and were expressed using pie charts.

\section{Results}

Majority of the participants were female clinicians, belonging to the age group of $20-30$ years. About $85 \%$ of the dentists knew the different methods of composite restoration [Figure 2]. 56\% of them felt that direct method is more efficient than indirect restoration. Majority of the dentists follow direct technique in their practice, with $69 \%$ having restored a cavity with direct technique [Figure 3]. About 39.1\% of the dentists answered that potential for repair is the main advantage of direct composite restoration, and $33.3 \%$ of dentists replied that increased strength of remaining tooth structure as the advantage of direct composite restoration [Figure 4]. 26.6\% of dental practitioners felt that better occlusion is the major advantage of indirect composite restoration, and $23.7 \%$ of dentists answered that minimising the effect of polymerisation shrinkage as the advantage of indirect composite restoration [Figure 5].

\section{Discussion}

Very few studies are done to evaluate the clinical efficiency of direct and indirect method of composite restoration. Currently, no surveys regarding the knowledge, awareness and perspective of direct and indirect method of composite restoration in class I cavities were conducted. Hence, this study was aimed to addressthe lacunae in the existing literature.

According to our study, majority of the clinicians agreed that the 
Figure 1. Questionnaire regarding Knowledge, Awareness and Perception among Clinicians about Direct and Indirect Method of Composite Restoration in Class I Cavity.

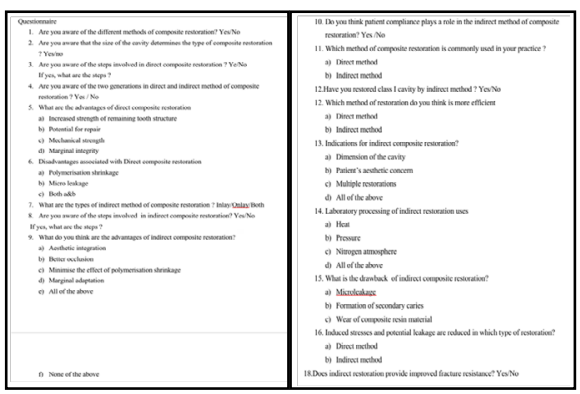

Figure 2. Awareness regarding the methods of composite restoration.

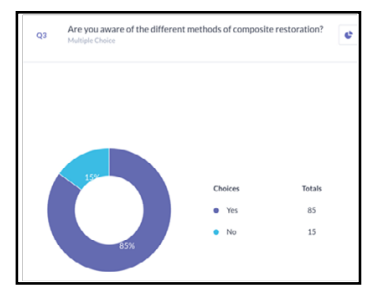

Figure 3. Method of composite restoration commonly used in dental practice.

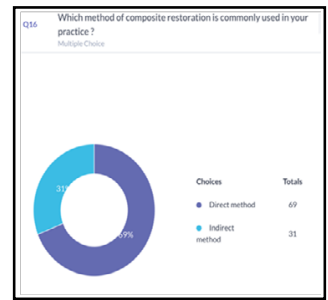

Figure 4. Advantages of direct composite restoration.

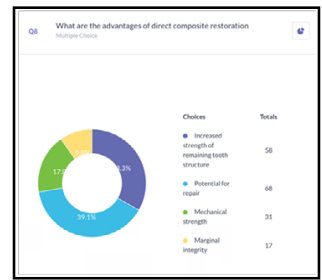

Figure 5. Advantages of indirect method of composite restoration.

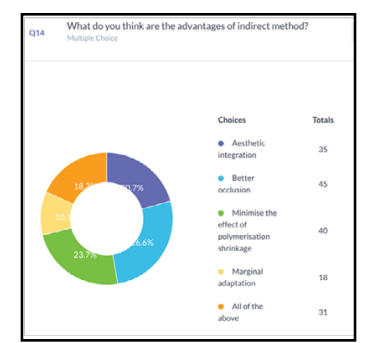

size of the cavity plays a major role in determining the type of restoration. The disadvantages of direct composite restoration were answered correctly by most of the clinicians, which was polymerisation shrinkage. Only about $73 \%$ of the dentists knew the steps involved in indirect method restoration. $75 \%$ of the practitioners felt that patient compliance plays a major role in indirect method of restoration. Majority of the dentists answered that formation of secondary caries was the major disadvantage. Hence, in our study, it was found that there is insufficient knowledge and awareness of the various pros and cons of indirect restoration.

Karaarslan et al., [23] performed a study on seventy patientsin which 140 teeth were equally divided into two groups $(n=70)$; Group-I -direct composite and Group-II -indirect composite. This study concluded that indirect restorations have less surface roughness, postoperative sensitivity, and soft-tissue irritation than direct restorations. The clinical efficiency of indirect restorations was more satisfactory than the direct restorations, which is in accordance to our study results. Scheibenbogen-Fuchsbrunner et al., [24] in their study equally divided 60 teeth into Group-I direct composite, and Group-II indirect composite. This study concluded that inlays demonstrated better anatomic form of the surface than direct restoration, which is similar to our study results.According to Fennis et al., [25] 176 premolars in 157 patients 
were divided equally into two groups. In this study, retention of the restoration was evaluated. This study concluded that there was no statistically significant difference between direct and indirect restorations.

According to Mendonça et al., [26] 76 teeth in 30 patients were divided into two groups: Group-I (Direct composite) $(\mathrm{n}=44)$ and Group-II Targis $(\mathrm{n}=32)$. The properties that were evaluated were surface texture, marginal discoloration, colour match, anatomic form, marginal integrity, and secondary caries. This study concluded that direct restorations performed better than indirect composite inlays for marginal integrity. According to our study, only $9.8 \%$ felt that marginal integrity was better in direct composite restoration and $10.7 \%$ of the dentists felt it was better in indirect composite restoration. Another study done by Cetin et al, [27] showed that there was no significant difference between the marginal integrity of direct and indirect composite restoration. According to Wassell et al., [28] 73 patients received 100 pairs of direct and indirect restorations, restored with the same material, which was Coltene BD. This study concluded that there was no significant difference in the clinical performance between direct and indirect technique and the direct inlay method gave no clinical advantage over conventional, incremental placement technique. The results were in accordance to our study outcome as majority of the dentists practiced only direct composite restoration.

Douglas et al., [29] in their study compared the microleakage in direct and indirect composite restoration, and concluded that indirect composite restoration had significantly reduced microleakage. Our study had contradictory results where in $30 \%$ of dentists felt that microleakage was a major drawback of indirect composite restoration. Dalpino et al., [30], conducted a study in 56 premolars to compare the fracture resistance in direct and indirect composite restoration. It was found that there was no significant difference between the two methods. In contrast clinicians in our study felt that indirect restoration has better fracture resistance. From our survey, it is evident that most of the dentists knew the different methods of composite restoration.

\section{Conclusion}

From our study it is evident that, dentists knew the method of indirect restoration, although most of them did not find this technique to be effective and hence did not practice. It is necessary to create awareness among the clinicians to practice indirect restoration technique for suitable patients with class I cavities.

\section{References}

[1]. Manhart J, Scheibenbogen-Fuchsbrunner A, Chen HY, Hickel R. A 2-year clinical study of composite and ceramic inlays. Clin Oral Investig. 2000 Dec;4(4):192-8.PubmedPMID: 11218488.

[2]. Anand VS, Kavitha C, Subbarao CV. Effect of Cavity Design on the Strength of Direct Posterior Composite Restorations: An Empirical and FEM Analysis. Int J Dent. 2011;2011:214751. PubmedPMID: 22216030.

[3]. Touati B, Pissis P. L'inlaycolle en resine composite. CahProthese. 1984;48:2959.PubmedPMID:6399476.

[4]. JAMES D. An esthetic inlay technique for posterior teeth. Quint Int. 1983;7:725-31.PubmedPMID: 6577498.

[5]. Lu H, Lee YK, Oguri M, Powers JM. Properties of a dental resin composite with a spherical inorganic filler. Oper Dent. 2006 Nov-Dec;31(6):734-40. Pubmed PMID: 17153985.

[6]. Mitra SB, Wu D, Holmes BN. An application of nanotechnology in advanced dental materials. J Am Dent Assoc. 2003 Oct;134(10):1382-90.
Pubmed PMID: 14620019.

[7]. Azeem RA, Sureshbabu NM. Clinical performance of direct versus indirect composite restorations in posterior teeth: A systematic review. J Conserv Dent. 2018 Jan-Feb;21(1):2-9. Pubmed PMID: 29628639.

[8]. Ericson D. What is minimally invasive dentistry?.J Am Dent Assoc. 2003 Jan;134(1):87-95. Pubmed PMID: 12555961.

[9]. Peutzfeldt A. Indirect resin and ceramic systems. Operative dentistry. 2001 Aug 1;26:153-76.

[10]. Miara P. Aesthetic guidelines for second-generation indirect inlay and onlay composite restorations. Pract Periodontics Aesthet Dent. 1998 May;10(4):423-31. Pubmed PMID: 9655049.

[11]. Howard NY. Advanced use of an esthetic indirect posterior resin system. Compendium of continuing education in dentistry (Jamesburg, NJ: 1995). 1997 Oct 1;18(10):1044-6.PubmedPMID: 9533312.

[12]. Dhoum S, Jabrane K, Dhaimy S, Talache LK, Ouazzani AE, Merini HE. Indirect Posterior Restoration: Composite Inlays. Biomed J Sci \&Tech Res. 2018;5(1):4312-6.

[13]. Mjör IA. Pulp-dentin biology in restorative dentistry. Part 7: The exposed pulp. Quintessence Int. 2002 Feb;33(2):113-35. Pubmed PMID: 11890026.

[14]. Malay KK, Duraisamy R, Brundha MP, Kumar MP. Awareness regarding anemia among 1 st year dental undergraduate students. Drug Invention Today. 2018 Aug $1 ; 10(8)$.

[15]. Kumar MS. Knowledge, attitude and practices towards oral health among law students in Chennai. Journal of Pharmaceutical Sciences and Research. 2016 Jul 1;8(7):650.

[16]. Kumar MP. Dental management of patients on antiplatelet therapy: Literature update. Asian J Pharm Clin Res. 2016;9(3):26-31.

[17]. Kumar S. Newer delivery systems for local anesthesia in dentistry. J Pharm Sci Res. 2015;7(5):252-5.

[18]. Ahamed A, Kumar MS. Knowledge, attitude and perceived confidence in handling medical emergencies among dental students. J IntSocPrev Community Dent. 2017 Nov-Dec;7(6):364-369. PubmedPMID: 29387622.

[19]. Kumar S. Knowledge, attitude and practices of dental students toward dental management of patients on antiplatelet therapy. Asian J Pharm Clin Res. 2016;9(30):270-6.

[20]. Gayathri MM. Knowledge, Awareness and Attitude among dental students about hepatitis B infection. Journal of Pharmaceutical Sciences and Research. 2016 Mar 1;8(3):168.

[21]. Kumar SM. Knowledge, Attitude and practices regarding needlestick injuries among dental students. Asian Journal of Pharmaceutical and Clinical Research. 2016;9(4):312-5.

[22]. Sivakumar N, Sundari KK, Chandrasekar S, Kumar MP. A review on smile arc-An orthodontist's perspective. Drug Invention Today. 2018 Sep 2;10.

[23]. Karaarslan ES, Ertas E, Bulucu B. Clinical evaluation of direct composite restorations and inlays: Results at 12 months. Journal of Restorative Dentistry. 2014 May 1;2(2):70.

[24]. Scheibenbogen-Fuchsbrunner A, Manhart J, Kremers L, Kunzelmann KH, Hickel R. Two-year clinical evaluation of direct and indirect composite restorations in posterior teeth. The Journal of prosthetic dentistry. 1999 Oct 1;82(4):391-7.

[25]. Fennis WM, Kuijs RH, Roeters FJ, Creugers NH, Kreulen CM. Randomized control trial of composite cuspal restorations: five-year results. Journal of Dental Research. 2014 Jan;93(1):36-41.

[26]. Mendonça JS, Neto RG, Santiago SL, Lauris JR, Navarro MF, de Carvalho RM. Direct resin composite restorations versus indirect composite inlays: one-year results. J Contemp Dent Pract. 2010 May 1;11(3):25-32.Pubmed PMID: 20461321.

[27]. Cetin AR, Unlu N, Cobanoglu N. A five-year clinical evaluation of direct nanofilled and indirect composite resin restorations in posterior teeth. Operative dentistry. 2013 Apr;38(2):E31-41.Pubmed PMID: 23215545.

[28]. Wassell RW, Walls AW, McCabe JF. Direct composite inlays versus conventional composite restorations: three-year clinical results. Br Dent J. 1995 Nov 11;179(9):343-9. Pubmed PMID: 7495630.

[29]. Douglas WH, Fields RP, Fundingsland J. A comparison between the microleakage of direct and indirect composite restorative systems. J Dent. 1989 Aug;17(4):184-8. PubmedPMID: 2671078.

[30]. Dalpino PH, Francischone CE, Ishikiriama A, Franco EB. Fracture resistance of teeth directly and indirectly restored with composite resin and indirectly restored with ceramic materials. Am J Dent. 2002 Dec;15(6):389-94. Pubmed PMID: 12691276. 